\title{
Corrigendum: lowa gambling task: there is more to consider than long-term outcome. Using a linear equation model to disentangle the impact of outcome and frequency of gains and losses
}

\author{
Annette Horstmann ${ }^{1,2 *}$, Arno Villringer ${ }^{1,2,3,4}$ and Jane Neumann ${ }^{1,2}$ \\ ' Department of Neurology, Max Planck Institute for Human Cognitive and Brain Sciences, Max Planck Society, Leipzig, Germany \\ 2 Integrated Research and Treatment Center Adiposity Diseases, Leipzig University Medical Center, Leipzig, Germany \\ ${ }^{3}$ Clinic for Cognitive Neurology, University Hospital Leipzig, Leipzig, Germany \\ ${ }^{4}$ Mind and Brain Institute, Berlin School of Mind and Brain, Humboldt University Berlin, Berlin, Germany \\ *Correspondence: horstmann@cbs.mpg.de
}

Edited by:

Björn Brembs, University of Regensburg, Germany

A commentary on

Iowa gambling task: there is more to consider than long-term outcome. Using a linear equation model to disentangle the impact of outcome and frequency of gains and losses

by Horstmann, A., Villringer, A., and Neumann, J. (2012). Front. Neurosci. 6:61. doi: 10.3389/fnins.2012. 00061
A mistake regarding the exemplary weights given in Table 4 of our original publication was recently brought to our attention. We corrected the weights and give the complete and updated table in this commentary.

Received: 23 April 2013; accepted: 14 May 2013; published online: 04 June 2013.

Citation: Horstmann A, Villringer A and Neumann J (2013) Corrigendum: Iowa gambling task: there is more to consider than long-term outcome. Using a linear equation model to disentangle the impact of outcome and frequency of gains and losses. Front. Neurosci. 7:90. doi: 10.3389/fnins.2013.00090

This article was submitted to Frontiers in Decision Neuroscience, a specialty of Frontiers in Neuroscience. Copyright (c) 2013 Horstmann, Villringer and Neumann. This is an open-access article distributed under the terms of the Creative Commons Attribution License, which permits use, distribution and reproduction in other forums, provided the original authors and source are credited and subject to any copyright notices concerning any third-party graphics etc.

Table 4 | (corrected): Example (one subject's) least squares solution of the linear equation model for mean choices in block 5.

\begin{tabular}{lcccc}
\hline Deck & Long-term outcome $\left(\boldsymbol{x}_{\mathbf{1}}\right)$ & Gain frequency $\left(\boldsymbol{x}_{\mathbf{2}}\right)$ & Loss frequency $\left(\boldsymbol{x}_{\mathbf{3}}\right)$ & -1.47 \\
\hline A & -0.86 & -0.86 & 0.34 & 0.15 \\
$\mathrm{~B}$ & -0.86 & 0.86 & 0.79 & 0.50 \\
$\mathrm{C}$ & 0.86 & -0.86 & 0.34 & 0.10 \\
D & 0.86 & 0.86 & 0.25 \\
\hline Weights & -0.145 & 0.110 & 0.089 \\
\hline
\end{tabular}

